\title{
Increasing Denture Retention using Compound Denture Technique - A Case Report
}

\author{
Agam Wirayudha, Michael Josef Kridanto Kamadjaja, Bambang Agustono \\ Department of Prosthodontics, Faculty of Dental Medicine \\ Universitas Airlangga \\ Surabaya - Indonesia
}

\begin{abstract}
Background: Treating missing tooth with denture, in some cases, still leave the patient unfulfilled. Good mastication and retention are the main considerations especially for those who require more retentions. In some cases, combination of partial and fixed denture the best approach to achieve better functional and retention results. Purpose: To report compound denture procedures with good mastication and retention as the main considerations. Case: A 43-year-old male patient reported a complaint of chewing difficulty due to missing right upper front teeth caused by work accident and extracted posterior. Patient wanted to wear partial denture to regain good mastication. Case management: Compound denture was chosen to optimize the remaining teeth for better functional and aesthetic. Zirconia all ceramic fixed dentures were fabricated on 13, 14, 15 with an occlusal rest on 13 and 15. Pontic on the 14 used ridge lap design. Discussion: Compound denture is a combination of removable and fixed denture where a minor connector of a removable denture should involve a fixed denture. Fixed denture shall be fabricated first and then removable denture. Conclusion: The definitive restoration of this case was compound denture, which is a combination of partial denture metal frame and fixed denture to restore the good mastication and retention.
\end{abstract}

Keywords: compound denture, fixed denture, partial denture, retention

Correspondence: Michael Josef Kridanto Kamadjaja, Department of Prosthodontics, Faculty of Dental Medicine - Universitas Airlangga, Surabaya 60132 - Indonesia, Telp: +62315030255 Email: michael-j-k-k@fkg.unair.ac.id

\section{INTRODUCTION}

Other than dental caries, missing tooth is another most common dental problem. Those who experienced partial missing tooth require jaw rehabilitation. ${ }^{1}$ Jaw rehabilitation requires proper diagnosis and treatment plan to achieve harmonious occlusion and articulation contact. Optimal stomatognathic function, supporting health and aesthetics for patients. More missing tooth requires more complex treatment. ${ }^{2}$ Several rehabilitation techniques can be used to determine the clinical condition comprehensively by considering the patient's oral health, function, comfort, and aesthetics. Prosthodontic treatments can cause occlusal changes. Unwanted occlusal changes should be avoided because they may cause iatrogenic or failure of restoration. ${ }^{7}$ Optimal oral health is the main goal of any rehabilitation procedures as it restores chewing function and oral health, as well as maintains such condition throughout patient's life. $^{8}$

This paper reports a patient with anterior and posterior missing tooth that requires restoration of chewing and aesthetic function. The patient's dental occlusion relationship was unstable due to broken and missing tooth. Posterior occlusion is considered stable if there is no disturbance on protrusive and lateral mandible movements. ${ }^{5}$ The goal of occlusion treatment is to balance the mastication pressure to prevent premature and excessive contact with the teeth. ${ }^{6}$ Compound denture design was selected to treat the missing tooth. Compound denture technique can increase the partial denture retention by utilizing the remaining teeth as fixedfixed bridge. ${ }^{3}$ Combining partial denture and fixed-fixed bridge requires operator skills and knowledge to obtain optimal results. This is to report the conducted compound denture treatment in optimizing the remaining teeth so that the patient regains good chewing function and more secure denture application.

\section{CASE}

A 43-year-old male patient visited the Universitas Airlangga Dental Hospital (RSGM), with main complain difficulty 
chewing food because many of his back teeth broken and extracted. The patient requested for denture treatment for him to eat comfortably. The patient had never used denture, no systemic disease, and was in good health. Extraoral examination found no complaint on the temporomandibular joint and palpation resulted no pain complaints. The conditions of face, eyes, nose and lips were normal. Intraoral examination, missing tooth $14,16,17,18,22,24,25,26$, $27,28,36,37,38,46,47,48$; dental caries on tooth 44 and 45 (Figure 1 and 2). Dynamic occlusion could not be determined, and static occlusion was only present on tooth 15 and 45 with cusp to marginal ridge posterior dental relationship. The overjet was around $4 \mathrm{~mm}$, and overbite was around $2 \mathrm{~mm}$. Radiographic interpretation showed diffuse radiolucent appearance at the apex tip of tooth 44 and radiolucent appearance of secondary caries on tooth 44 and 45 (Figure 3). From the anamnesis, clinical and radiographic examination, the diagnosis of tooth 44 was chronic apical periodontitis due to pulp necrose; while the diagnosis of tooth 45 was irreversible pulpitis.

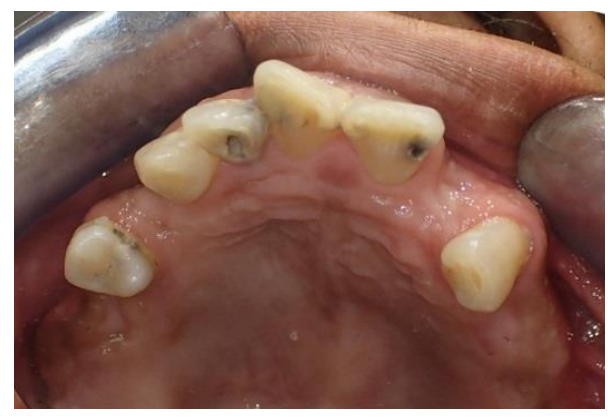

Figure 1. Clinical view of upper jaw from occlusal side.

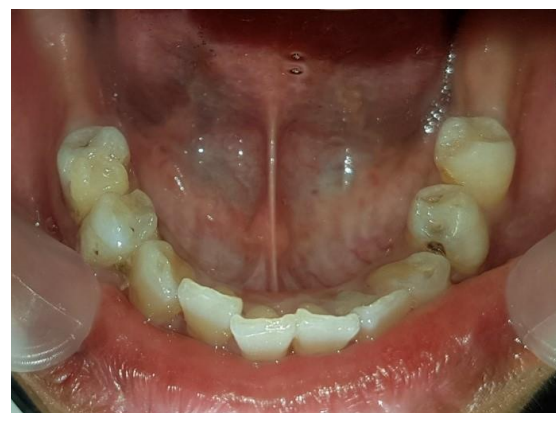

Figure 2. Clinical view of lower jaw

\section{CASE MANAGEMENT}

This case management was initiated with upper and lower jaws scaling treatments, endodontic treatment of tooth 44 and 45 , and followed with restoration of tooth 44 and 45 with composites. After completion, examination on masticatory muscles stability and temporomandibular joints (functional evaluation), measurement on vertical dimension of occlusion and preliminary bite determination were conducted. The VDO value (Vertical Dimension Occlusion) was then printed with putty in regions 13 and 15 to make temporary crown from self-curing resin. Abutment tooth 13 and 15 were prepared with chamfer shape on the cervical area. The fixed partial denture was made of pure zirconia with saddle point and occlusal rest on ceramic crowns 13 and 15 . Once the denture finished, the insertion was done using freegenol temporary cement. The patient stated no complaints during the control one week later. Fixed partial denture was permanently applied with fixed luting cement (Fuji I) (Figure-4).

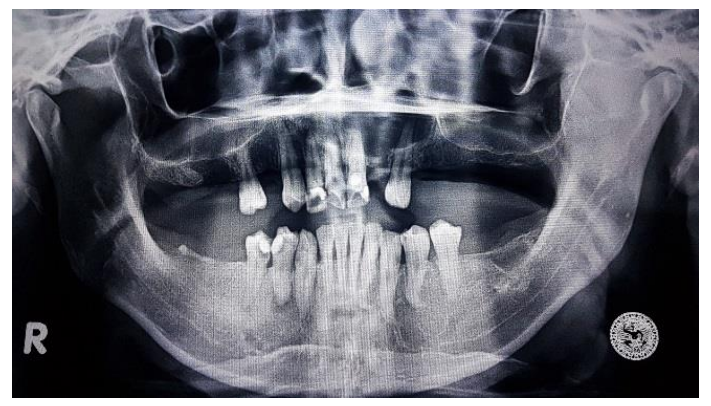

Figure 3. Radiological examination with panoramic photgraphs.

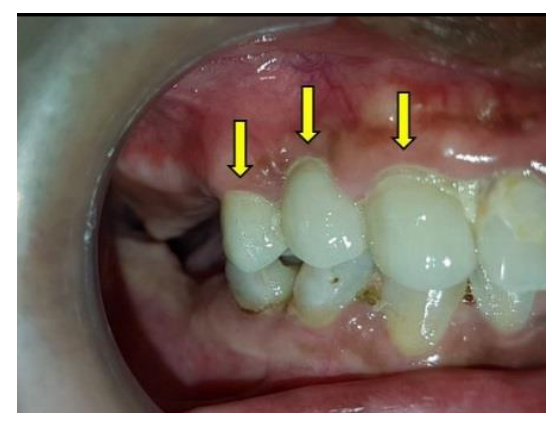

Figure 4. Clinical view of 3 fixed denture units at 13, 14, 15 .

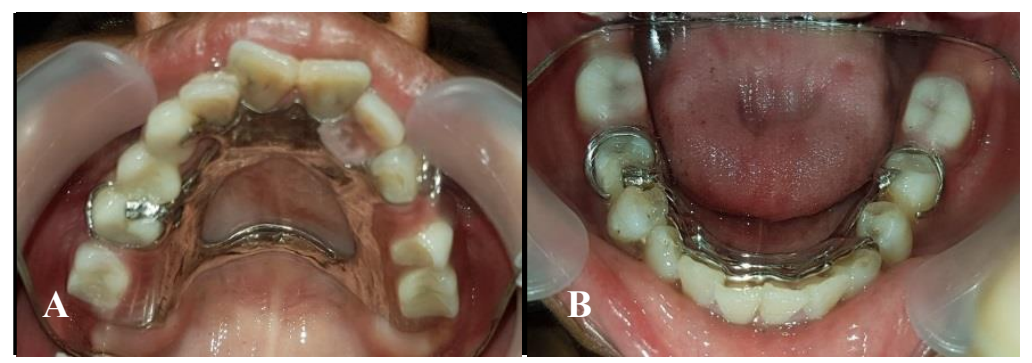

Figure 5. Clinical view of metal frame insertion. (A) Upper view (B) lower view 
Once permanent insertion of fixed partial denture completed, maxillary and mandibular metal frames were made. Preparation of mesio-occlusal rest on tooth 35 and 45. Next, functional models of the maxilla and mandible were printed using alginate. Molding was done on the upper jaw first as the denture base was more stable and broader than the lower jaw. Also, upper jaw printing was easier. The functional model printing used stock tray made of alginate as functional model produces more match and accurate result. All seals of stock tray were applied tightly by the mucosa and while moving the mucosa, the patient was requested to pronounce "I" and "U".

The functional model was then mounted on a nonadjustable articulator with a preliminary bite registration guide. It was then sent to the dental technician for metal frame making. The patient tried the metal frame. The metal frame was well-fitted to the patient. All occlusal rests were well on place. Contact bites of upper and lower jaws were good. The following step was application of teeth elements. Tooth color selection was done with the patient's consent. Once dental elements arranged, the patient tried to wear it again. The contact relationship between upper and lower jaws were good. Yet, once the acrylic denture base completed, there was bite disharmony on jaw relation. Selective grinding was done until the patient feels comfortable. (Figure-5).

One day after the insertion of removable dentures, the patient visited for first control. The patient experienced pain on gingiva regional 46 . This was overcome by performing selective grinding on the referred acrylic surfaces. The patient was given instructions on how to clean and store the denture. The patient was also recommended to consume soft food. The second control was carried out on the third day after the first control. The patient visited without complaints about the denture, and the patient began to feel comfortable. Information and Education Communication was re-conveyed to the patient. The patient was permitted to consume foods in general. ${ }^{2}$

\section{DISCUSSION}

Missing posterior teeth can cause a variety of abnormalities. Missing loss in a long time can result in various negative impacts, some of them are supraposition and extrusion of antagonistic teeth. It also can cause shifts or movement of the teeth next to them. This is due to uneven chewing pressure received by the teeth. Vertical load that is received by teeth can cause teeth to move or shift. ${ }^{6}$ From the results of clinical examination, there were only 6 remaining maxillary teeth, namely tooth $11,12,13,15,21$ and 23 , and there were 8 remaining mandibular teeth. In this case, the patient requested a denture for better chewing and secure denture application. Compound denture is a combination of fixed and removable denture and is indicated for cases without loss of median teeth.

Compound denture was selected for the patient as it adds the partial denture retention. Fixed denture 13, 14 and 15 was made to increase the removable partial denture retention. Tooth 13 and 15 had good prognosis to be used as abutment teeth. The teeth were in vital condition; there was no resorption of alveolar crest bone on the tooth region; the result obtained was $2 \mathrm{~mm}$ pocket depth on the mesial, distal, labial and palatal sides; bleeding on probing examination confirmed no bleeding; and no loose tooth. These conditions were in accordance with the requirements. Tooth supporting tissue is considered healthy if the gingival sulcus is $\pm 2 \mathrm{~mm}$ deep; pink gingiva; gingival size does not enlarge, and there is no bleeding; supported by healthy bones and no loose tooth ${ }^{9}$. Fixed denture on tooth 13,14 , and 15 was made of pure zirconia. Zirconia or zirconium is white metal gray, crystalline (amorphous), can be forged and resistant to fire if pure. ${ }^{9}$ Pure zirconia material is suitable because fixed dentures do not break easily when tooth 13 and 15 are fitted with occlusal rest metal frames.

The partial denture was applied to maxilla and mandible. The indications of partial denture are missing teeth with long edentulous areas, presence of resorption or damage to alveolar bone, absence of abutment teeth for fixed dentures, periodontal tissue not unable to support fixed dentures, lower costs and patient's preference ${ }^{10}$. This case reports treatment with compound denture, which is a combination of partial metal frame denture and fixed denture, to restore chewing function properly and good retention.

\section{REFERENCES}

1. Katsoulis J, Nikitovic SG, Spreng S, Neuhaus K, MericskeStern R. Prosthetic rehabilitation and treatment outcome of partially edentulous patients with severe tooth wear: 3-years result. J Dent 2011; 39 (7): 662-671.

2. Wassel R, Naru A, Steele J, Nohl F. Applied occlusion. United Kingdom: Quintessence Publ Co. Ltd., 2008: 31-48.

3. Attin T, Filli T, Imfeld C, Schmidlin PR. Composite vertical bite reconstructions in eroded dentitions after $5 \cdot 5$ years: a case series. J Oral Rehabil 2011; 39(1): 73-9.

4. Raigrodski AJ, Dogan S. Concepts and considerations of tooth wear. II. The mechanical component. Practical Procedures \& Aesthetic Dentistry 2008; 20 (3): 220.

5. Di Matteo AM. Pounding on the occlusion pulpit. Inside Dentistry 2008; 4(3): 102-10.

6. Burke FJ, Kelleher MG, Wilson N, Bishop K. Introducing the concept of pragmatic esthetics, with special reference to the treatment of tooth wear. J Esthet Restor Dent 2011; 23(5): 277-93.

7. Sudhir N and Parkash H. Full mouth rehabilitation with group function occlusal scheme in a patient with severe dental fluorosis. Indian Journal of Dental Advancements 2011; 3(3): 627-31.

8. Tashkandi, E, 2009, Effect of Surface Treatment on The Micro-Shear Bond Strength to Zirconia, The Saudi Dental J.,21 (3):113-116

9. Carranza FA, Newman MG, Takei H, Klokkevold PR. Newman and Carranza's Clinical Periodontology. 13th Ed. Elsevier 2016. p. 236, 242

10. Gunadi. 2012. Buku Ajar Ilmu Geligi Tiruan Sebagian Lepasan Jilid I. Jakarta, Hipokrates, pp 14

11. Sheng W, Zou P, Zhang aiping. Elastic Resin And Casting Frame Compound Denture For Double Teeth Ended Free Deletion. Shenzhen Traditional Chinese Medical Hospital, Shenzhen 518033, 2004. China 